\title{
Developing and Implementing an Educational Program about Strategies of Conflict Resolution for the Head Nurses Working at Main Assuit University Hospital
}

\author{
Hanaa Mohammed Ahmed, Prof. Dr.Hoda Diab Fahmy Ibrahim, Prof. Dr. Hala \\ Ramzy Yousef \& Dr. Sahar Mohamed Morsy. \\ Assistant lecturer in Nursing Administration Department. Prof. of Community Health Nursing, Faculty of \\ Nursing - Assuit University Faculty of Nursing - Assuit University Assist. Professors of Nursing Administration - \\ Faculty of Nursing- Assuit University
}

\begin{abstract}
Background: Conflict is a power struggle in which a person intends to harass, neutralize, injure or eliminate a rival.

Aims: to developing and implementing an educational program about strategies of conflict resolution for the head nurses working at the Main Assuit University Hospital.

Study subject: included all head nurses who have 10 years of experience and more.

Study tools included three tools, personal characteristics tool, knowledge test (pre, post and follow up), and Participants opinion tool.

Results: It were a statistical significant difference between the head nurses' knowledge regarding all items of educational program content in pre, post and follow up.

Conclusion: head nurses had satisfactory knowledge immediately after implementing of the educational program content.

Recommendation: Follow up the head nurses application of mediation and negotiation styles of conflict resolution formats by continuous evaluation of retained knowledge.
\end{abstract}

Keywords: Conflict management, Head nurses, Educational program, Mediation and Negotiation.

\section{Introduction}

Nursing is a profession that is based on collaborative relationships with clients and colleagues. When two or more people view issues or situations from different perspectives, these relationships can be compromised by conflict. Conflict refers to a power struggle in which a person intends to harass, neutralize, injure or eliminate a rival (Tomey, 2009). Conflict is commonly perceived as being a negative issue. However, the experience of dealing with conflict can lead to positive outcomes for nurses, their colleagues and clients. Traditionally, conflict has been viewed as a destructive force to be ignored or silenced; today, many are redefining conflict as an opportunity (Davies, 2010). Once the conflict is approached as a cooperative effort, nurses and other healthcare professionals can restructure trust to enhance professional relationships (Collins, 2012).

Conflict that managed effectively by nurses can lead to personal and organizational growth. If conflict is not managed effectively, can hinder a nurse's ability to provide quality client care and escalate into violence and abuse. So, nurses need to be aware of the ways in which conflict can escalate and be prepared to prevent or manage it in the workplace. Conflict resolution styles are avoiding, competing, collaborating, compromising, accommodating, mediation and negotiation (Daiski, 2014). By understanding the dynamics of mediation and negotiation in areas such as leadership, power, and conflict management, healthcare professionals will improve the quality of their professional practice, relationships and their working environment (Berman, 2014).

Mediation is a voluntary, non-binding, private dispute resolution process, through a neutral person helps the parties to reach the negotiated settlement (Schlairet, 2009). It included the following styles: facilitative, evaluative and transformative mediation, Facilitative mediation, in which the mediator structure a process to assist the parties in reaching a mutually agreeable resolution (Tomey, 2009).

Negotiation is a process of digging into an issue to identify underlying individual concerns and find alternatives that meet most or all sets of concerns (Collins, 2012). Negotiation in its most creative form is similar to collaboration and in its most poorly managed form may resemble a competing approach. It frequently resembles compromise when it is used as a conflict resolution strategy (Novak, 2012).

Mediation and negotiation are procedures for resolving opposing preferences between the parties (Fiumano, 2012). Negotiation involves discussion between the parties with the goal of reaching agreement. There is no limit to the number of parties ("disputants") who can take part in negotiation, but two-party 
negotiations are the kind most often studied (Nastakis, 2013). Mediation is a variation on negotiation in which one or more outsiders ("third parties") assist the parties in their discussion. When the organization relies upon its employees to help achieve an objective by evaluating staff members' strengths, as wells as understanding their knowledge, skills, motivations and resources, the organization can reduce inefficient redundancy to provide thoughtful development tools on an ongoing basis for successful staff development and needs assessment balance the needs and goals of the organization and its staff members'(Gustafson, 2013).

\section{Significance of the study}

It was noticed that there were no studies done in Upper Egypt about mediation and negotiation as strategies for conflict management. So, the researcher desirous to study the phenomenon among head nurses through developing and implementing an educational program about mediation and negotiation at Main Assuit University Hospital.

\section{Aims of the study:}

To developing and implementing an educational program about strategies of conflict resolution for the head nurses working at the Main Assuit University Hospital.

\section{Specific objectives:}

1. Plan; develop an educational program about conflict management strategies, mediation and negotiation as styles of conflict management.

2. Implement an educational program for developing conflict management strategies, mediation and negotiation as styles of conflict management.

3. Evaluation of the program effectiveness on head nurses knowledge and outcomes of the program by opinions of the participants.

\section{Subject and method: The present study was composed of:-}

\section{A-Technical design:}

It involves the research design, setting, subjects, and tools of data collection.

\section{Research design:}

A quasi-experimental design was used in this study.

\section{Setting of the study:}

The present study conducted at Main Assuit University hospital with a bed capacity ( $\mathrm{n}=1789)$ beds. The implementation of the program carried out at the continuing training and education center at Assuit University.

\section{Subject and sample of the study:}

The present study included all head nurses who have 10 years of experience and more $(\mathrm{n}=44)$. Convenient sample was used in the present study.

Tools of the study: it includes three tools as the following:

1-Personal characteristics tool: used to collect data about the study subject who participated in the program, age, unit, and years of experience in the hospital, level of education, and, previous workshops or programs was attendance especially in conflict resolution strategies.

\section{2- Knowledge test (pre, post and follow up test):}

It developed by the investigator to assess head nurses' knowledge regarding conflict resolution strategies. The test was administered to the studied participants before implementation of the program, after implementation of the program, and follow up after three months. It covers 105 question classified into eight categories as the following:

1- Conflict management content (10 questions).

2- Conflict resolution strategies (3 questions).

3- Traditional conflict resolution styles (5 questions).

4- Mediation as an alternative conflict resolution style (8 questions).

5- Negotiation as an alternative conflict resolution style (6 questions).

6- Conflict prevention (5 questions).The participants' responses based on by a correct response scored (2) correct incomplete response scored (1) and incorrect scored (zero).

7- The mediator role (37 questions classified into 6 categories).

8- The negotiator role ( 31 questions classified into 3 categories).

The participants were answered by yes scored (one) or no scored (zero) and used class group and individual exercises during program implementation. 
Scoring system: the sum of correct answer total grade were computed if the scores percent of responses were $\geq$ $60 \%$, this means satisfied knowledge but $\leq 60 \%$ this means unsatisfied knowledge.

3- Evolution of the program: It was form developed by the investigator to evaluate the worth of the program from participants to point of view. It covers questions (16) questions classified into two categories as the following:

1- The program content (10 questions).

2- The appropriateness of the educational programs (6 questions).

The participants' responses based on 5 points likert scale ranging from (5) excellent, (4) very good, (3) good, (2) pass and (1) poor.

\section{B- Operational design:-}

After reviewing the available literatures concerning the topic of the study, Translation of the assessment tools from English to Arabic was done. It took about Four months from September to December 2013 and the validity of the assessment tool reviewed by the experts of the nursing administration (Jury from three expertise in the specialty) to check the relevance, coverage, and clarity of the questions. Accordingly, modifications were done and the final form was developed. This phase took about two months from February to March; 2014.this design explains the steps of actual implementation of the study, including the pilot study and the field work.

\section{Field work:}

- Planning and developing an educational program:

The program was planned and designed based on the needs assessment. The data were collected by the researcher through questionnaire with the head nurses. The researcher had explained the questionnaire to each one. The time taking with each participant was from 15-20 minutes. This phase took about three months from June to August, 2014. Analysis of the results of head nurses needs their working at main Assiut University Hospital.

\section{The planning phase included the following:}

- Formulating program objectives and timetable of the program

A) General objectives of the program:

To equip the participants with knowledge regarding different strategies of conflict resolution, especially for mediation and negotiation styles at main Assiut University Hospital.

B) Specific objectives of the program: by the end of the program the participant able to:

-Discuss how to manage of conflict, apply skills used to conflict resolution.

-Enumerate conflict resolution strategies and give examples about traditional conflict resolution styles.

-Enumerate alternatives conflict resolution styles.

-Discussion mediator roles.

-Apply roles of negotiator to resolve of conflict.

-Determine how to prevent of the conflict.

\section{- Implementation of the program:}

The program was implemented by the investigator on the representative sample of 44 head nurses for two weeks, divided into two groups; every group was 22 to avoid shortage of head nurses at all units. The total time of the program was 20 hours distributed into 10 sessions for each group and due to fill classroom courses private workers during the implementation of the present program forced to split the participants into two groups.

- Teaching strategies these used:

- Lecture.

- Small group discussion.

- Brain storming.

-Case study.

- $\quad$ Teaching aids these used:

-Handouts were provided to all participants.

-PowerPoint.

-Flip charts and, photographs and drawing for illustrations. 
-Video presentation.

After endin of the educational program distributed of the certificates for participants.

- Evaluation of the program:

The investigator used questions to evaluate the following:

1- Outcome of the program: It was used to evaluate cognitive skills of program content through pre, post and follow up tests after three months.

2- Worth of the program "learner's feelings about the program": This can be evaluated through the use of:

1. A structured questionnaire that asks the participants about the effectiveness of the program.

2. Participation and attendance of participants in learning sessions are available indication of program effectiveness.

\section{C-Administrative design:-}

Official permission obtained to collect data from the directors of the Main Assiut University Hospital, official permission obtained to collect necessary data and application of the program from general director of Nursing, director of Nursing Administration department at Main Assiut University Hospital and the director of the continuing education and training center.

\section{Ethical consideration:}

- Oral consent taken from the participants in the present study.

- Written consent taken from the participants through document dating before the program implemented.

\section{D- Statistical design:-}

Collected data were verified prior to computerized data entry and analysis by using statistical software package for social sciences (SPSS) v.g 20.program. Data were presented using descriptive statistics in the form of percentages also mean and standard deviations were calculated. For relation between variables (chi - square) and (ANOVA test) were used, statistical significant was considered at $\mathrm{P}$ - value $\leq 0.05$.

\section{Results}

Fig. (1): Personal characteristics of the studied head nurses included in the educational program.

\begin{tabular}{|c|c|c|}
\hline Items & No. & $\%$ \\
\hline \multicolumn{3}{|l|}{ 1-Age: } \\
\hline $30-40 \downarrow$ & 27 & 61.4 \\
\hline $40-50 \downarrow$ & 12 & 27.2 \\
\hline 50 and more. & 5 & 11.4 \\
\hline \multicolumn{3}{|l|}{ 2-Years of experience: } \\
\hline $10-15 \downarrow$ years. & 27 & 61.4 \\
\hline 15 and more. & 17 & 38.6 \\
\hline \multicolumn{3}{|l|}{ 3-Level of education: } \\
\hline Master degree in nursing science. & 6 & 13.6 \\
\hline Bachelor degree in nursing science. & 38 & 86.4 \\
\hline \multicolumn{3}{|l|}{ 4-Previous attendance workshops or training program: } \\
\hline Yes & 29 & 65.9 \\
\hline No & 15 & 34.1 \\
\hline \multicolumn{3}{|l|}{ If answered ( yes) motioned it: } \\
\hline - Human resources development & 8 & 18.1 \\
\hline - Infection control & 2 & 4.5 \\
\hline - Human resources development \& Infection control & 4 & 9.1 \\
\hline - Infection control \& First aid & 2 & 4.5 \\
\hline - Human resources development - Infection control \& English level & 2 & 4.5 \\
\hline - Human resources development - Infection control \& ICTP & 4 & 9.1 \\
\hline $\begin{array}{l}\text { - Infection control, how to prevent occupational hazards, How to deal with emergency patients \& } \\
\text { How to deal with patients with heart disease and how to work CPR. }\end{array}$ & 5 & 11.4 \\
\hline - Human resources development - Infection control, ICTP \& preparation of a university teacher. & 2 & 4.5 \\
\hline
\end{tabular}

N.B:All participants not attended of any workshops or training program about conflict management. 
Fig. (1): Distribution of the studied head nurses accordance to the work settings.

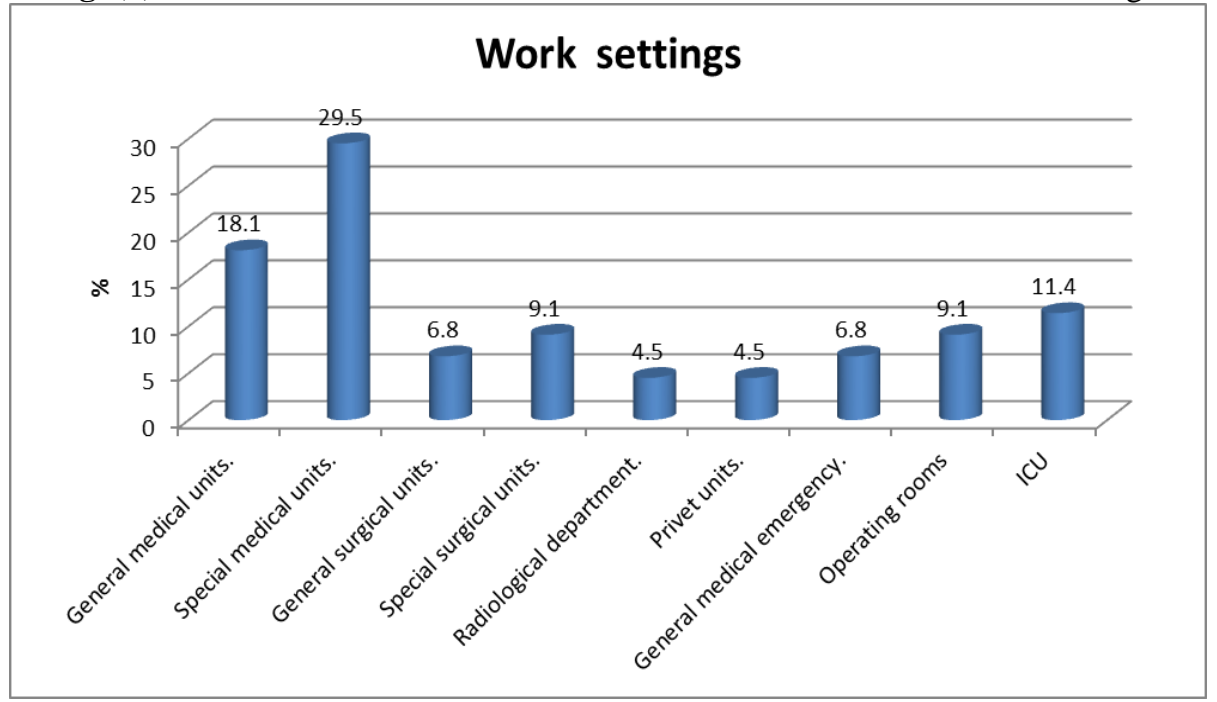

Figure (2): Comparison of studied head nurses knowledge regarding the conflict management content in pre, post and follow up of the educational program.

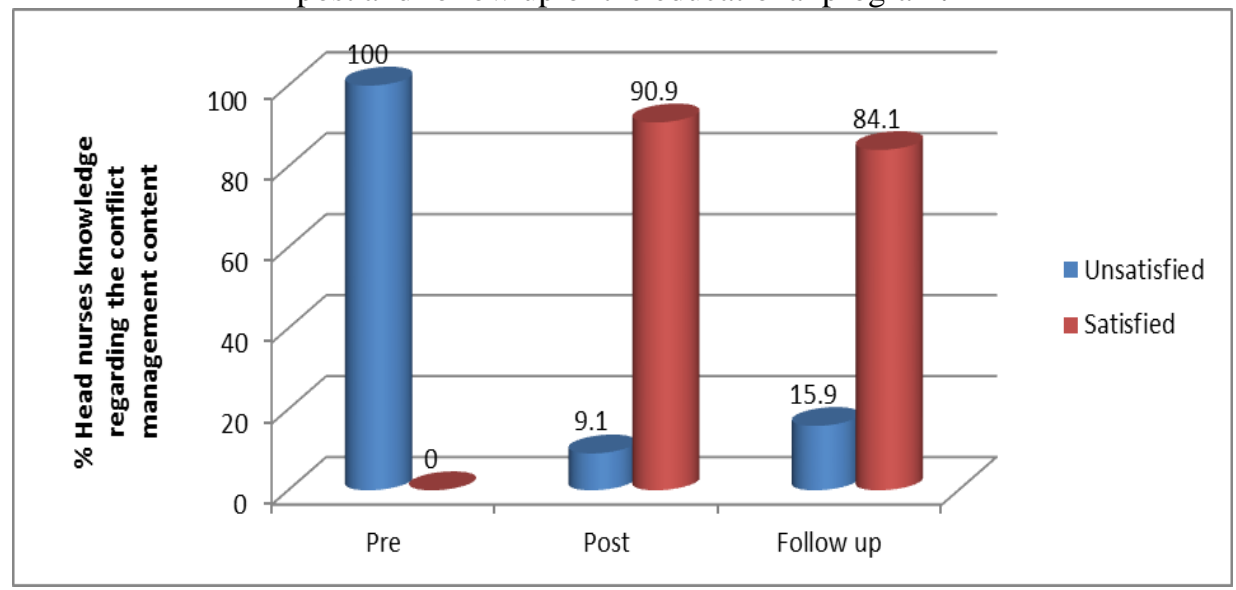

$(<60=$ unsatisfied, $>60$ satisfied $)$

Fig (3): Comparison of studied head nurses knowledge regarding the conflict resolution strategies in pre, post and follow up of the educational program.

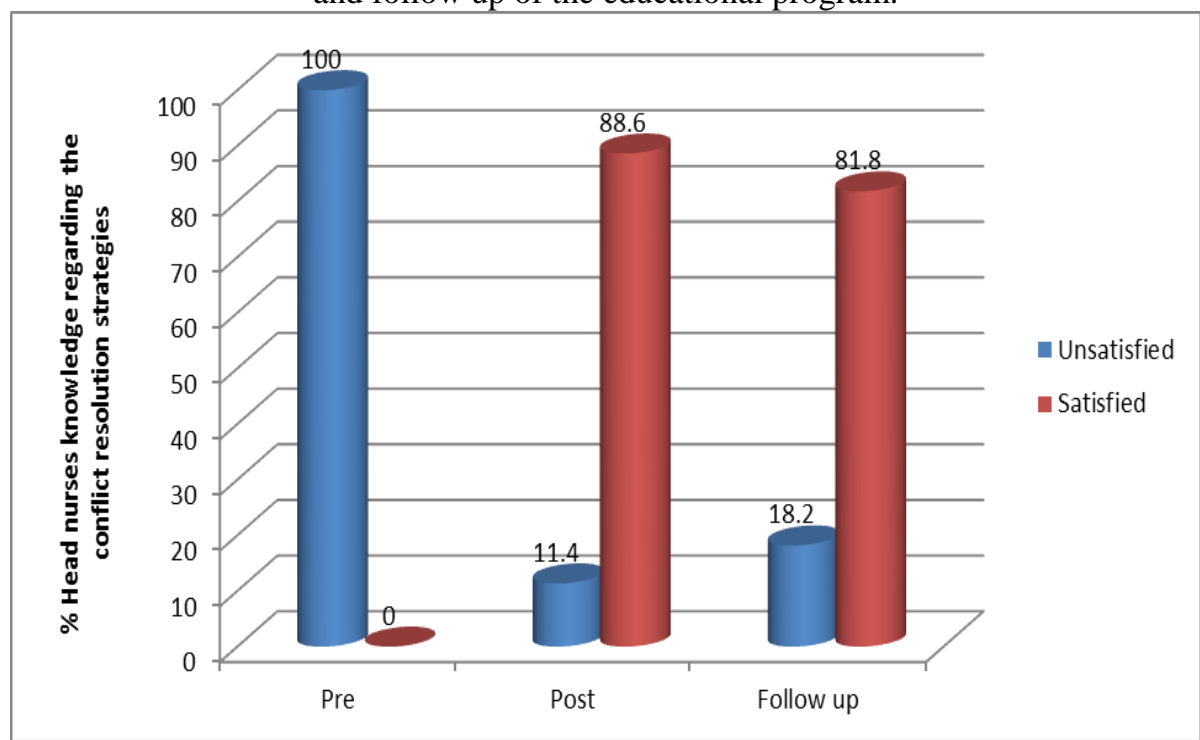

$(<60=$ unsatisfied, $>60$ satisfied $)$ 
Developing and Implementing an Educational Program about Strategies of Conflict Resolution for..

Figure (4): Comparison of studied head nurses knowledge regarding the traditional conflict resolution styles in pre, post and follow up of the educational program.

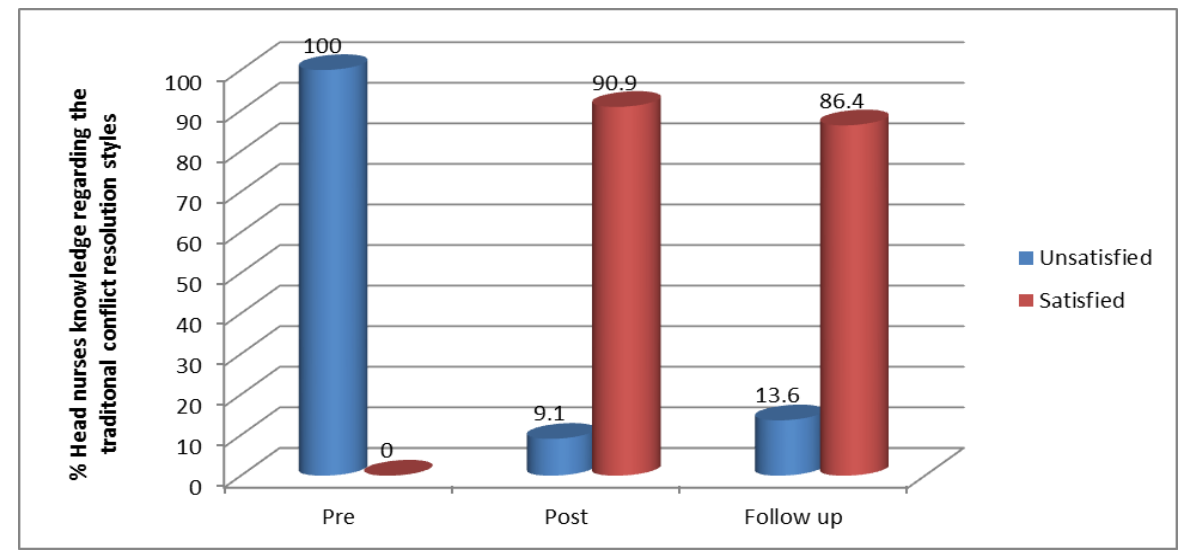

(<60=unsatisfied, $>60$ satisfied $)$

Figure (5): Comparison of studied head nurses knowledge regarding the mediation style content in pre, post and follow up of the educational program.

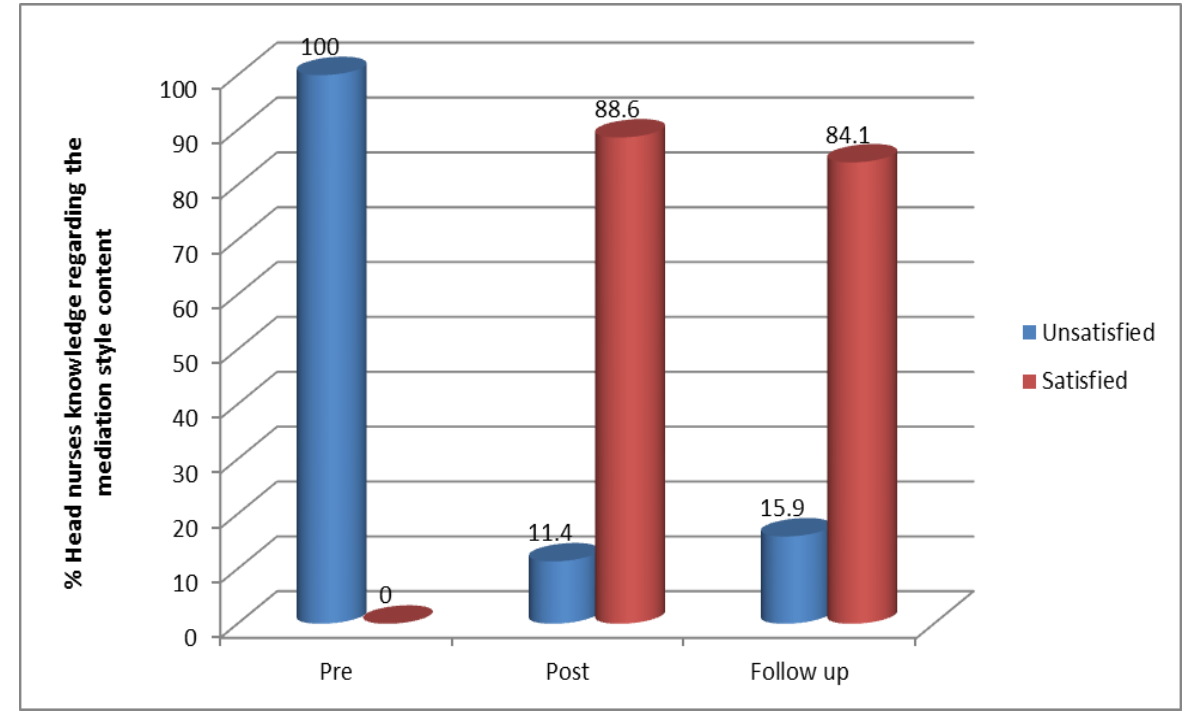

$(<60=$ unsatisfied, $>60$ satisfied $)$

Figure (6) Comparison of studied head nurses knowledge regarding the role of mediator in pre, post and follow up of the educational program.

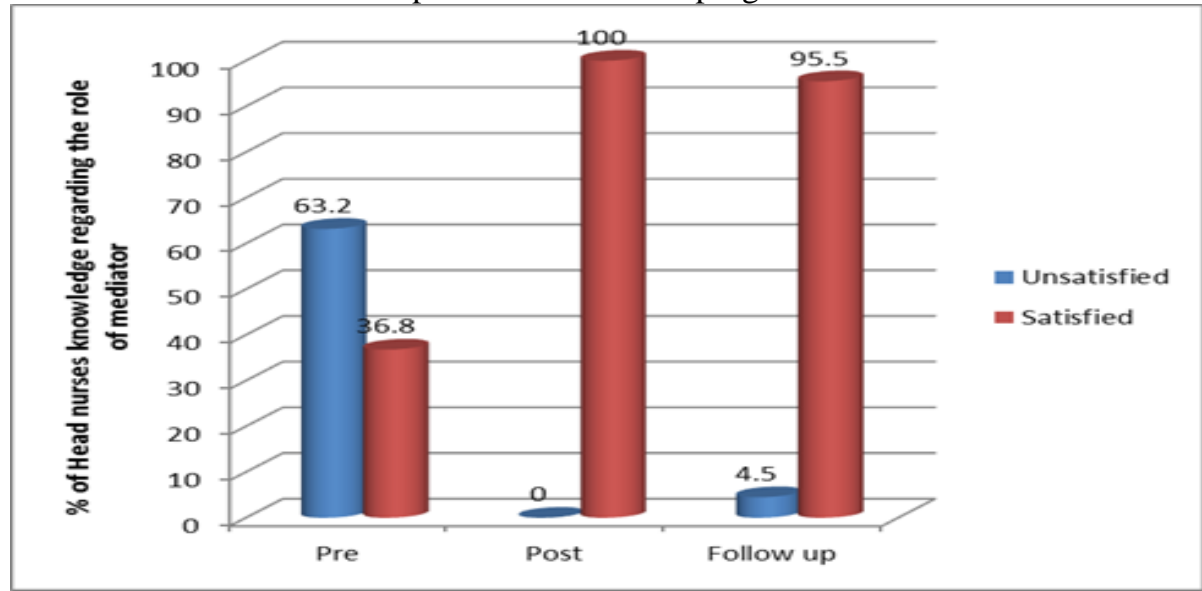

$(<60=$ unsatisfied, $>60$ satisfied $)$ 
Figure (7): Comparison of studied head nurses knowledge regarding the negotiation style content in pre, post and follow up of the educational program.

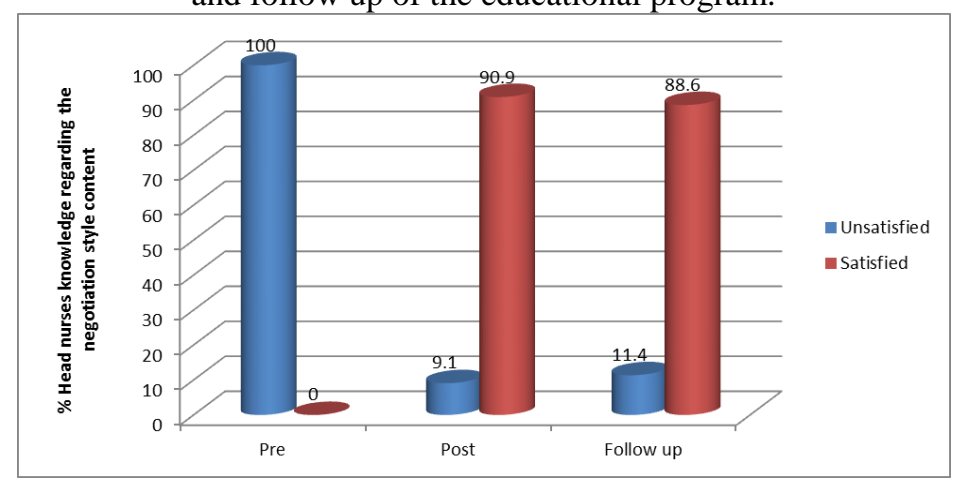

$(<60=$ unsatisfied, $>60$ satisfied $)$

Figure (8): Comparison of studied head nurses knowledge regarding the role of negotiator in pre, post and follow up of the educational program.

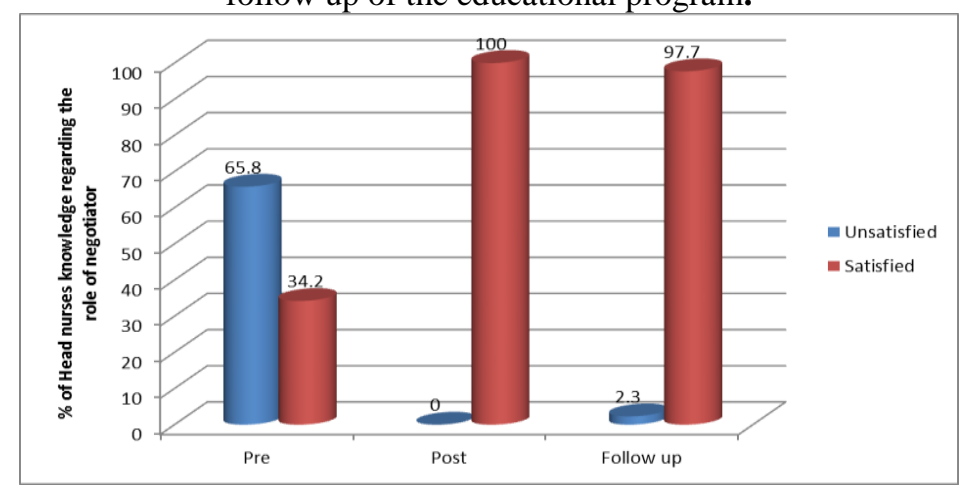

$(<60=$ unsatisfied, $>60$ satisfied $)$

Figure (9): Comparison of studied head nurses knowledge regarding the conflict prevention in pre, post and follow up of the educational program.

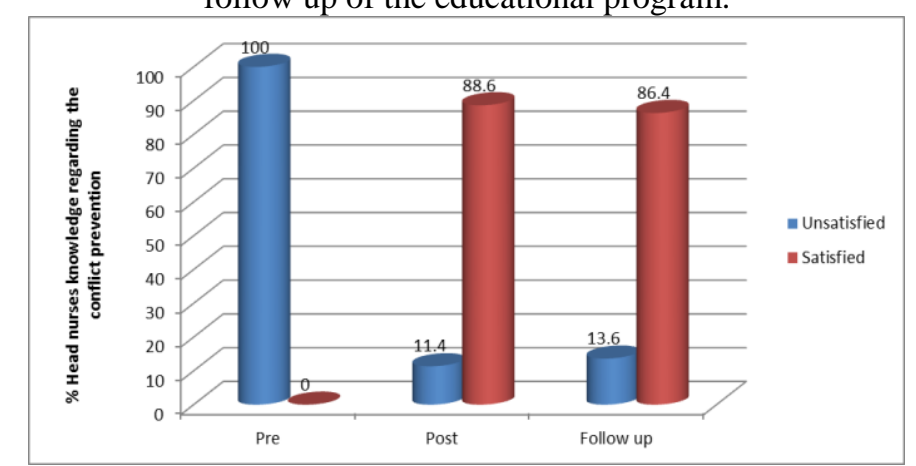

(<60=unsatisfied, $>60$ satisfied $)$

Table (2): Head nurses total knowledge regarding the educational program content pre, post and follow up.

\begin{tabular}{|c|c|c|c|c|c|c|c|c|}
\hline \multirow[t]{3}{*}{ Item } & & \multirow[t]{2}{*}{ Pre } & \multirow[t]{2}{*}{ Post } & \multirow[t]{3}{*}{ Follow up } & \multicolumn{2}{|c|}{ Pre - post } & \multicolumn{2}{|c|}{ Pre - follow up } \\
\hline & & & & & \multirow{2}{*}{ T1 } & \multirow{2}{*}{$\begin{array}{l}\text { P1. } \\
\text { value }\end{array}$} & \multirow{2}{*}{$\mathbf{T 2}$} & \multirow{2}{*}{ P2. Value } \\
\hline & & \multicolumn{2}{|l|}{ Mean \pm SD } & & & & & \\
\hline 1. & Conflict management content. & $1.3 \pm 2.4$ & $19 \pm 2.3$ & $17.1 \pm 2.1$ & 7.1 & $0.001 * *$ & 6.4 & $0.001 * *$ \\
\hline 2. & Conflict resolution strategies. & $1.66 \pm 2.61$ & $8.32 \pm 1.38$ & $7.22+0.79$ & 6.6 & $0.001 * *$ & 6.4 & $0.001 * *$ \\
\hline 3. & Conflict resolution styles. & $1.1 \pm 2.6$ & $20.5 \pm 3.3$ & $18.4 \pm 2.9$ & 6.4 & $0.001 * *$ & 5.9 & $0.001 * *$ \\
\hline 4. & Mediation style. & $1.2 \pm 1.8$ & $14.9 \pm 2.3$ & $13.4 \pm 2.1$ & 4.4 & $0.001 * *$ & 4.2 & $0.001 * *$ \\
\hline 5. & Role of mediator. & $20.98 \pm 8.55$ & $36.93 \pm 0.45$ & $36.93 \pm 0.45$ & 5.7 & $0.001 * *$ & 5.4 & $0.001 * *$ \\
\hline 6. & Negotiation style. & $1.61 \pm 2.68$ & $15.3 \pm 1.92$ & $14.2 \pm 0.98$ & 11.2 & $0.001 * *$ & 9.8 & $0.001 * *$ \\
\hline 7. & Role of negotiator. & $19.64+9.76$ & $30.86 \pm 0.55$ & $30.86 \pm 0.55$ & 8.4 & $0.001 * *$ & 7.7 & $0.001 * *$ \\
\hline 8. & Conflict prevention. & $1.66 \pm 2.61$ & $9.32 \pm 1.38$ & $8.22+0.79$ & 6.6 & $0.001 * *$ & 6.4 & $0.001 * *$ \\
\hline
\end{tabular}


(**) statistically significant.

Figure (10): Head nurses opinion's regarding the program content of the educational program.

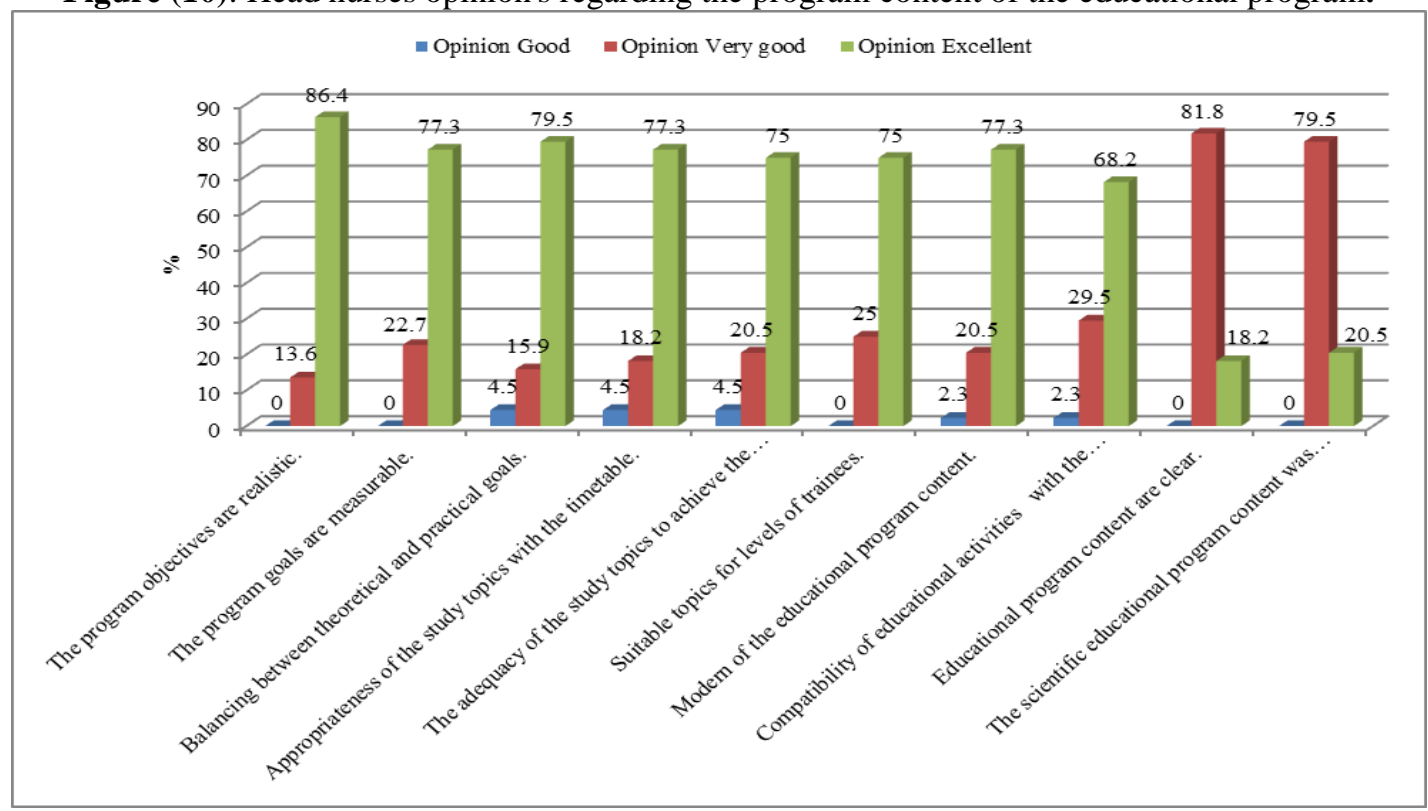

Figure (11): Head nurses opinion's regarding the appropriateness of the educational program at Main A.U.H. $(n=44)$.

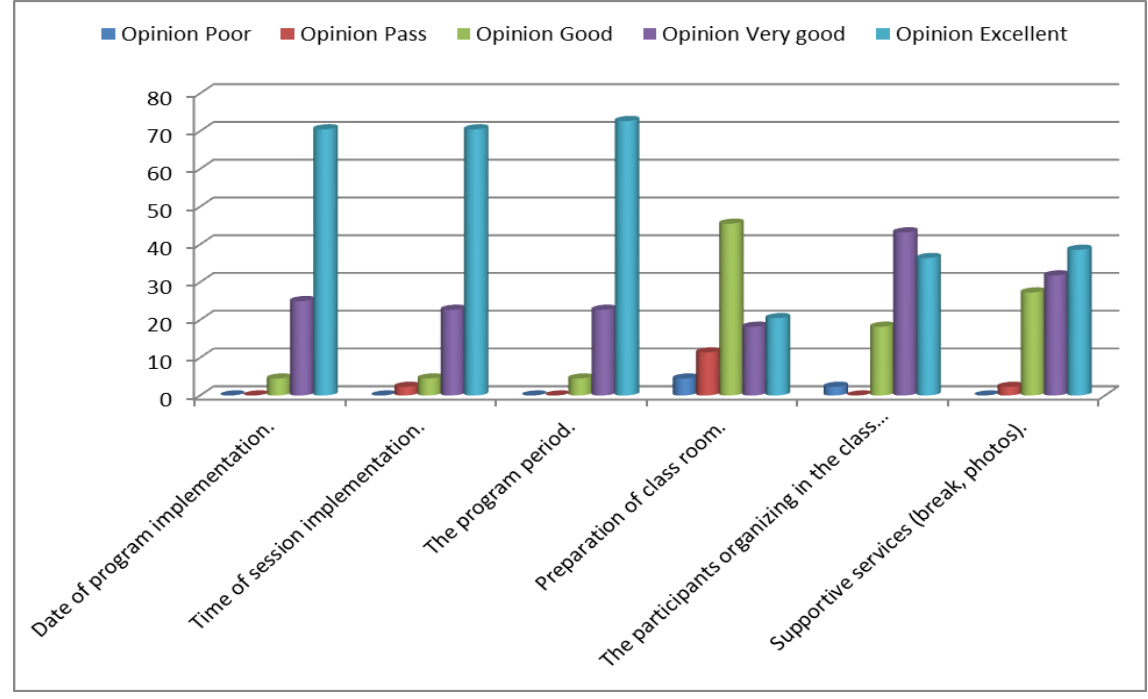

Table (1): Described that, personal characteristics of the studied head nurses in the educational program. The highest percentage of them have bachelor degree of nursing science, their age $30-40 \downarrow$ years old, and having experience from 10 to less than 15 years $(\mathbf{8 6 . 4 \% , 6 1 . 4 \% , ~ a n d ~ 6 1 . 4 \% ) ~ r e s p e c t i v e l y . ~ A l s o , ~}(\mathbf{6 5 . 9 \% )}$ of them had attended training courses and $\mathbf{( 1 8 . 1 \% )}$ of them attended human resources development course.

Distribution of the studied head nurses accordance to the work settings showed at Main Assiut University Hospital $(n=44)$ in figure (1). The highest percentage of the studied head nurses regarding the work settings in special medical units $\mathbf{( 2 9 . 5 \% )}$.

Comparison of studied head nurses knowledge regarding the conflict management content in pre, post and follow up of the educational program revealed in figure (2). The studied head nurses knowledge at post implementation of the educational program was satisfactory.

Comparison of studied head nurses knowledge regarding the conflict resolution strategies in pre, post and follow up of the educational program revealed in figure (3). The studied head nurses knowledge at post implementation of the educational program was satisfactory.

Comparison of studied head nurses knowledge regarding the traditional conflict resolution styles in pre, post and follow up of the educational program demonstrated in figure (4). The studied head nurses knowledge at post implementation of the educational program was satisfactory. 
Comparison of studied head nurses knowledge regarding the mediation style content in pre, post and follow up of the educational program depicted in figure (5). The studied head nurses knowledge at post implementation of the educational program was satisfactory.

Comparison of studied head nurses knowledge regarding the role of mediator in pre, post and follow up of the educational program described in figure (6). The studied head nurses knowledge at post implementation of the educational program was satisfactory.

Comparison of studied head nurses knowledge regarding the negotiation style content in pre, post and follow up of the educational program described in figure (7).The studied head nurses knowledge at post implementation of the educational program was satisfactory.

In figure (8): describes comparison of studied head nurses knowledge regarding the role of negotiator in pre, post and follow up of the educational program. The studied head nurses knowledge at post implementation of the educational program was satisfactory.

Comparison of studied head nurses knowledge regarding the conflict prevention in pre, post and follow up of the educational program described in figure (9). The studied head nurses knowledge at post implementation of the educational program was satisfactory.

Head nurses knowledge regarding the educational program content pre, post and follow up revealed in table (2).The highest statistical significant differences was found between studied head nurses in knowledge pre, post and follows up as regard to the all educational program content items $(\mathbf{P}=\mathbf{0 . 0 0 1})$. This means improvement of total knowledge for head nurses at all items in the post educational program.

Head nurses opinion's regarding the course content of the educational program revealed in fig. (10). The highest percentage of the studied head nurses have excellent as regard to terms, the program objectives are realistic and followed educational program are clear item this have very good score $(\mathbf{8 6 . 4 \%} \& \mathbf{8 1 . 8 \%})$ respectively.

Figure (11): depicts that, head nurses opinion's regarding the appropriateness of the educational program. The great majority of head nurses had excellent as regard to the program period and followed items the date of program implementation and the time of session implementation and there have the highest percentage in very good score for item the participants organizing in the class room $(\mathbf{7 2 . 7 \%}, \mathbf{7 0 . 5 \%} \& \mathbf{4 3 . 2 \%})$ respectively.

\section{Discussion}

The present study was conducted with the aim to developing and implementing an educational program about strategies of conflict resolution for the head nurses working at Main Assuit University Hospital.The current study revealed that a highly statistical significant difference between head nurses knowledge about all items of conflict management content in pre, post and follow-up of the educational program. There were a highest percentage of them knowledge immediately after implementation of the program (posttest). This finding in agreed with the study of Harawy, (2010) who showed that the positive impact of the educational program about conflict management and resolution improving knowledge the supervisors and nurse managers. Also, Abo Gad, \& El-Demerdash, (2014) who demonstrated that the effectiveness of training program for nursing managers that enhancing their knowledge and skills after implementation of the program.

This study finding was found improving of nurse manager in using upgrading of knowledge after implementing the educational program. A highly statistically significant difference in head nurse's knowledge in pre, post and follow up regarding the conflict management strategies and traditional conflict resolution styles.

These finding reflect that, Anthony et al., (2005) mentioned that conflict resolution is a key role of managers and a skill which every nurse manager needs to possess to retain staff. Also, in this respect Welford, (2010) reported that through informal learning such as journal clubs, reflective groups, in-service sessions and committees, and through formal educational programs of conflict resolution strategies, nurses can develop a repertoire of contemporary knowledge and skills to enhance their roles. Furthermore Brinkert, (2011) who did in-service and continuing education programs for nurse managers should be continually implemented. Staff development programs, using videotape, debriefing sessions and case study, would assist all of them to become aware of how can contribute to the overall management strategies used styles for conflicts resolution.

The foregoing study was consistent with Yoder, (2012) who reported that in preprogram, low percentage of studied head nurses were strong in using of competition, compromise, avoidance and accommodation styles, as well as using of collaboration style, regarding the post program and reached to all nursing manager were strong in using of competition style. Also, the majority of them were strong in using of compromise, avoidance, collaboration and accommodation styles.

Additionally the present study finding was congruence with Abo Gad \& El-Demerdash, (2014) who studied the significant improvement at nursing managers` levels in using of conflict management styles post program than preprogram. Preprogram a low and equal percent of nursing managers were strong in using of competition, compromise, avoidance and accommodation styles. As well as, $20 \%$ of them were strong in using 
of collaboration strategy, which changed post program and reached to all nursing manager were strong in using competition style. A highest percent of them were strong in using of compromise, avoidance, collaboration and accommodation styles.

After implementation of the educational program in current study, it was found that a high percentage of the studied head nurses had a high knowledge regarding all items of mediation alternative conflict resolution styles; this indicated that education and training program has an effect on the nursing managers and managing conflicts. This was in line with Berman, (2012) who had asserted that the effect of mediation training program on the studied subject was positive and had a high knowledge after implementation of this program about their ability to explored listening for understanding, reframing and elevating the definition of the problem to decrease the level of conflict.

The current study revealed that a highly statistically significant of the studied head nurses knowledge in pre, post and follow up of the educational program as regard to all items of mediator role. This finding was consistent with the study of Gerardi, (2010) who mentioned that, the professional nurse can play a mediator role in creating a healthy work environment by fostering collaborative relationships and showed, the components of the mediator role which including educating staff, serving as a role model, developing and working in collaborative and interdependent relationships, and establishing effective linkages to accomplish goals.

There were highly statistical significant differences between studied head nurses knowledge regarding all items of negotiation style content in pre, post and follow up of the educational program. This supported by suggested of Sullivan \& Decker, (2009) suggested that, conflict resolution can occurred when tension is decreased, and negotiation and problem solving were done to find beneficial and mutually agreeable solutions. The aftermath can be negotiation, peace building, or reconciliation that prevents the reoccurrence of the conflict, or the conflict could reoccur and escalate again.

On the other hand Yoder, (2012) mentioned that the training and education in negotiation as an alternative style of conflict resolution can provide healthcare professionals with the skills and expertise to help them deal with workplace conflicts, provides a safer and more satisfying environment for everyone. Moreover Sales training American, (2013) assured that, one-day training course regarding the negotiation styles can help the nurse manager to understand how conflict develops and how to interact with all parties to discover effective solutions. This highly interactive in using practice-driven class, case studies, small group interaction, videotapes and role-plays to help gain experience in using proven negotiation style in real-life situations. Will gain an understanding of the needs of different behavioral styles and how can lead to misunderstanding and conflict, as well as ways to work with each of those styles to find peaceful solutions.

There were had highly statistically significant of studied head nurses knowledge in pre, post and follow up about all items of prevention conflict, With this respect the finding study of Feng, \& Wilson, (2011) who mentioned that, a few organizations can afford to have professional counselors on the staff and given some training and educational program about how to prevent conflict, in which the nurse managers may be able to perform listening with understanding to express one's feelings to a concerned and understanding listener was enough to relieve conflict occurred among staff nurses.

Generally, this finding of the study revealed that a highest percentage of the studied head nurses had satisfactory knowledge about all content of the educational program immediatlly after implementing of the program. Lastly, the fact that the head nurses didn't continue to use the handouts that received during educational program due to lack of time to read because of the overload in their units, this underscores the importance of continuing education. With this respect Dutta, (2013) who emphasized that most forgetting occurred because information in short term memory. However, forgetting can also occur because nurses may lose their abilities to recall information that is in long term memory this agree with the present study.

\section{Conclusion}

It was a statistical significant difference between studied head nurses knowledge regarding the all items of educational program content in pre, post and follow up (P. value $=\mathbf{0 . 0 0 1} * *)$ and a marked improvements in head nurses' knowledge immediately after implementation of the educational program content (\%88.6,\%90,9,\%100)respectively.

\section{Recommendation}

In the light of the results of this study, the following recommendations are suggested.Follow up the head nurses application of mediation and negotiation conflict resolution styles formats by continuous evaluation of retained knowledge.Refreshing courses about conflict management should be provided periodically, to help head nurses acquainted with the new knowledge. Further research studies are needed to evaluate nurse's skills of conflict resolution, assess administrative interventions to manage organizational conflict. Further research studies are needed to assess the dynamics of the hospitals and work environment to identify the contributing 
factors of nurses behavior, and to identify subordinates perception of conflict resolution strategies and traditional and alternative styles of conflict resolution and utilize by their head nurses.

\section{References}

[1]. Abo Gad, R. \& El-Demerdash, S.(2014): An Educational Program about Nursing Managers`Transformational Leadership, Conflict management Styles and Decision Making Effectiveness IOSR Journal of Nursing and Health Science 3, (3), P.P. 42-56. Retrieved from: www.iosrjournals.org

[2]. Anthony, M., Standing, T., Glick, J., Duffy, M., Paschall, F., Sauer, M., Sweeney, D., Modic, B., \& Dumpe, L. (2005): Leadership and nurse retention: The pivotal role of nurse managers. Journal of Nursing Administration, 35:P.p.146-155.

[3]. Berman, L. (2012): Mediation's Evolution in SoCal: Where it has been and where it is going by Brilliant Results Magazine, by the American Arbitration Association, Retrieved from: lee jay@mediationtools.com.

[4]. Berman, L. (2014): 13 Tools for Resolving Conflict in the Workplace, with Customers and in Life by Brilliant Results Magazine, by the American Arbitration Association, Retrieved from: lee jay@mediationtools.com.

[5]. Brinkert, L. (2011): Alternative dispute resolution: Managing upsets and keeping people safe. Evidence-based Healthcare and Public Health. 8(6):P.p.412- 413.

[6]. Collins, W. (2012): Manage Conflict and Resolve Problems by Negotiating, by Colorado mediators \& arbitration usadr. Available at: http:// www, books Google. com.eg.

[7]. Daiski, I. (2014): Changing nurses' dis-empowering relationship patterns. Journal of Advanced Nursing, 48 (1), P.p, 43-50.

[8]. Davies, C. (2010): A zero tolerance abuse policy- what does an RN need to consider? Alberta RN journal, 62(4), P.p. 8-9.

[9]. Dutta, P. (2013): What is The Definition of Staff Development? by Demand Media,. Available at: http:// www, books Google. com.eg.

[10]. Feng, D. \& Wilson, B. (2011): Managing issues of resistance and sex stereotyping when conducting gender awareness workshopsRetrieved from: http:// nursingworld.org.

[11]. Fiumano, J. (2012): Navigate through conflict, not around it. Nursing Management Journal, 36(8), P.P., 1-14. Retrieved from: https://books.google.com.eg/books?isbn=0803640560

[12]. -Geradi, D. (2010): Using mediation techniques to manage conflict and create healthy work environments. American Association of Critical care Nurses Clinical issues, 15(2), P.p.95- 182.

[13]. -Gustafson, J. (2013): Professional profile on LinkedIn Experience developing and presenting staff development. Retrieved from:

[14]. www.linkedin.com/pub/janelle-gustafson/69/37www.taayuon.4youth.org.

[15]. -Harawy, D. (2010): Analysis of the conflict management and resolution training on employee stress at a health care organization, hospital topics, 83 (4), P.p 11-17.

[16]. Nastakis, D. (2013): Negotiation skills for physicians. Am Journal Surg. 1(8), P.p185, available at: www.Wikimedia Foundation.

[17]. Novak, K. (2012): Conflict Negotiation Guidelines Section 4, Policy Toolkit for Strengthening Health Sector Reform, P.p 4-29, available at: www. Wikimedia Foundation.

[18]. Sales training American, (2013): Getting to Yes: Negotiating Agreement without Giving In. 2nd Ed. New York: Penguin by Ury W, B Patton. Available at: www.Wikimedia Foundation.

[19]. Schlairet, C. (2009): Bioethics mediation: The role and importance of nursing advocacy, Nursing Outlook Journal, 57, (4), P.p 185193.

[20]. Sullivan, E. \&Decker, P. (2009): Effective Leadership and Management in Nursing. 7th Ed, by Prentice London Inc. Available at: https://books.google.com.eg/books.

[21]. -Tomey, M. (2009): Guide to nursing management and leadership 8th edition, P.p 146- 159 by Elsevier inc.

[22]. Welford, V. (2010): Nurse-physician workplace collaboration. Online Journal of Issues in Nursing, 5(1), P.622.Retrieved from: http://nursingworld.org.

[23]. Yoder, W. (2012): The common conflict-handling mode used in nurse/physician interactions, by Institute of Healthcare Improvement. Retrieved from: https://books.google.com.eg/books 